\title{
PENERAPAN PRINSIP KEHATI-HATIAN KOPERASI (STUDI DI KSPPS BMT MASLAHAH)
}

\author{
Saifuddin Syuhri \\ Email: saifuddin@gmail.com \\ Universitas Islam Zainul Hasan Genggong \\ Nurul Fadila \\ Universitas Islam Zainul Hasan Genggong
}

\begin{abstract}
Prudential Principles Can Provide Protection for Cooperatives in Relation to Savings and Loans Agreements Implemented As for the precautionary principle arrangements can provide protections for cooperatives in connection with savings and loan agreements which carry out lending is one form of money lending, in a loan agreement money is often required there are debt guarantees which can consist of various forms and types. Debt guarantees in positive law in Indonesia, there are various laws and regulations that govern or relate to debt guarantees which are often referred to as collateral law. The provisions of the applicable guarantee law provide arrangements that will protect the parties concerned with the loan of money, financing and debt guarantees. The cooperative as a business entity that provides financing to Members is required to make security measures so that the financing can be paid off by the Member concerned. Financing which is not paid by the Members either in whole or in part will be a loss for the Cooperative. Losses indicate a relatively large amount that will affect the health of the Cooperative and the continuation of the Cooperative business. Therefore, no matter how small the value of money from financing that has been given to Members must remain secured in accordance with the precautionary principle. In general, financing safeguards can be carried out through the financing analysis stage and the application of applicable legal provisions. The link between credit collateral and credit security can be concluded from the provisions of Article 1131 of the Civil Code so that it is another effort or alternative that can be used by the Cooperative to obtain credit repayment when the debtor defaults.
\end{abstract}

Keywords: Prudential Principle, Financing at KSPPS BMT MASLAHAH 


\section{PENDAHULUAN}

Koperasi lahir pada permulaan abad ke 19 (sembilan belas), sebagai reaksi terhadap sistem revolusi industri dan penerapan sistem kapitalis, pada saat itu ada sebagian kelompok yang menguasai kehidupan perekonomian yaitu mereka yang memiliki uang atau modal baik di pedesaan maupun di perkotaan. Koperasi dipergunakam oleh masyarakat golongan ekonomi lemah, terutama buruh yang berpenghasilan sangat kecil dengan tujuan untuk memecahkan persoalan ekonominya akibat tekanan pemilik modal yang menyebabkan ekonominya semakin melemah.

Perkembangan perekonomian perkoperasian menjadi suatu sistem dalam kehidupan ekonomi masyarakat untuk memenuhi kebutuhan hidup dan memecahkan permasalahan ekonomi yang dihadapi. Koperasi mengandung unsur kekeluargaan, pemerataan, keadilan sosial, dan kesejahteraan bagi seluruh rakyat. Dalam menggerakkan Koperasi dibutuhkan keterampilan teknik, pengetahuan ekonomi, sosial dan ketekunan serta disiplin tertentu sesuai dengan dinamika keprofesionalan dan keaktifan dari anggota yang terlibat dalam Koperasi saat ini dan mendatang. Mohammad Hatta dalam bukunya The Cooperative Movement in Indonesia, mengemukakan bahwa Koperasi adalah usaha milik bersama untuk memperbaiki nasib penghidupan ekonomi berdasarkan tolong menolong.

Koperasi seperti diatur dalam Undang-undang Nomor 25 Tahun 1992 tentang Perkoperasian pasal 1 ayat (1) adalah badan hukum yang didirikan oleh orang perseorangan atau badan hukum koperasi dengan pemisahan kekayaan para anggotanya sebagai modal untuk menjalankan usaha yang memenuhi aspirasi dan kebutuhan bersama di bidang ekonomi, sosial dan budaya sesuai dengan nilai dan prinsip koperasi.

Salah satu jenis Koperasi yang cukup berkembang di Indonesia adalah Koperasi Simpan Pinjam (KSP). Koperasi Simpan Pinjam (KSP) ialah Koperasi yang bergerak dalam lapangan usaha pembentukan modal melalui 
tabungan- tabungan para anggota secara teratur dan terus- menerus untuk kemudian dipinjamkan pada para anggota dengan cara mudah, bunga ringan, cepat dan tepat untuk tujuan produktif dan kesejahteraan. ${ }^{1}$ Kondisi ini berjalan dari waktu kewaktu dan mencapai belasan bahkan puluhan tahun. Para penggerak menyadari bahawa pengorbanan yang dilakukan adalah semata dengan tujuan utama untuk melayani sesama.

Kegiatan pokok unit ini adalah kegiatan yang dilakukan untuk menghimpun dana dan menyalurkannya melalui kegiatan usaha simpan pinjam dari dan untuk anggotanya, calon anggotanya dan koperasi lain serta anggotanya yang memerlukan dana.

Praktek simpan pinjam di koperasi yang selama ini dijalankan dengan menggunakan model tanpa jaminan/agunan, sebenarnya kurang memenuhi persyaratan pemberian pinjaman yaitu $5 \mathrm{C}$ adalah terpenuhinya syarat pertama yaitu Character, dimana seorang debitur harus dilihat bagaimana wataknya apakah jujur atau tidak. Syarat kedua adalah Capital yaitu besaran pinjaman yang hendak diberikan harus lebih kecil dibanding kekayaan/modal yang dimiliki oleh debitur. Syarat ketiga adalah Capacity, artinya adalah rencana usaha yang akan didanai harus memiliki prospek yang bagus dikemudian hari, karena hal ini akan berkait dengan kemampuan seorang debitur untuk mengembalikan kewajibannya tepat waktu. Sedangkan syarat keempat adalah Colleteral atau jaminan, hal ini merupakan syarat mutlak yang harus dipenuhi karena ketika debitur ingkar janji (wanprestasi), maka jaminan yang diagunkan tersebut dapat dijadikan alat untuk memenuhi kewajibannya. Syarat kelima adalah condition of economic, hal ini merupakan syarat eksternal yang harus dimiliki oleh debitur terhadap keberlangsungan usahanya dimasa yang akan datang, apakah usaha yang akan dibiayai sifatnya musiman atau merupakan kebutuhan pokok yang dapat dilakukan setiap hari. Demikian juga pengaruhnya terhadap kondisi perekonomian secara umum, apakah usaha

\footnotetext{
${ }^{1}$ Ninik Widiyanti, Sunindhia,Y.W, 2003, Koperasi dan Perekonomian Indonesia Cetakan keempat, Rineka Cipta, Jakarta, hlm. 54
} 
yang dimiliki debitur mempunyai ketahanan usaha bisnisnya atau rentan dengan kondisi perekonomian tertentu yang mudah hilang, rusak atau beresiko tinggi.

Oleh karena itu, untuk menanggulangi kredit macet pemerintah mengeluarkan pedoman pelaksanaan Peraturan Menteri Negara Koperasi, Dan Usaha Kecil Dan Menengah Republik Indonesia Nomor 19/Per/M.KUKM/XI/2008 tentang Pedoman Pelaksanaan Kegiatan Usaha Simpan Pinjam Oleh Koperasi dan diimbangi dengan pengendalian internal yang kuat sebagai kegiatan koperasi yang sehat dan aman dalam manajemen koperasi tersebut serta menjalankan prinsip kehati-hatian yang dicantumkan dalam pasal 19 ayat 2 Peraturan Menteri Negara Koperasi, Dan Usaha Kecil Dan Menengah Republik Indonesia Nomor 19/Per/M.KUKM/XI/2008 tentang Pedoman Pelaksanaan Kegiatan Usaha Simpan Pinjam Oleh Koperasi yang berisi tentang penjelasan pelaksanaan pemberian pinjaman koperasi harus memperhatikan prinsip kehati-hatian dan asas pemberian pinjaman yang sehat yang prinsip tersebut dalam pemberian pinjaman yang sehat dengan memperhatikan penilaian kelayakan dan kemampuan pemohon pinjaman sehingga memberikan kemanfaatan bagi koperasi dan anggotanya, yang peraturan tersebut dibuat sebagai dasar kegiatan operasional koperasi yang sehat dan aman dalam pemberian kredit.

Dari penjelesan diatas Penulis berharap dapat menemukan implementasi yang dipergunakan dalam penerapan asas kekeluargaan dan penerapan prinsip kehati - hatian dalam perjanjian kredit pada koperasi, guna menjadikan informasi dan pelajaran bagi Koperasi Simpan Pinjam (KSP) di kemudian hari.

Adapun rumusan masalahan yang akan diangkat yaitu :

Bagaimana seharusnya pengaturan prinsip kehati-hatian agar dapat memberikan perlindungan bagi koperasi sehubungan dengan perjanjian simpan pinjam yang dilaksanakan? 


\section{PEMBAHASAN}

\section{A. GAMBARAN UMUM KSPPS BMT MASLAHAH}

Perkembangan zaman yang semakin meningkat, seiring dengan diperkenalkannya ekonomi industry 4.0 Koperasi yang berbasis syariah, dituntut untuk lebih berkembang dan agresif dalam menghadapi tantangan ekonomi industry tersebut. Salah satu Koperasi yang terus mengembangakan eksistensinya hingga sekarang adalah Koperasi Simpan Pinjam dan pembiayaan Syari'ah (KSPPS) BMT Maslahah.

Koperasi ini didirikan tepatnya pada tanggal 12 Rabiul Awal $1418 \mathrm{H}$ bertepatan dengan tanggal tahun 1997 dengan nama KJKS BMT MMU Sidogiri yang berkedudukan di Kecamatan Wonorejo Kabupaten Pasuruan, dengan modal Rp. 13.500.000,- dengan beranggotakan 348 orang, terdiri dari asatidz dan pengurus dan pimpinan pondok pesantren sidogiri. Pada tanggal 4 september tahun 1997 disahkan menjadi BMT MMU, dengan badan hokum Koperasi menjadi Koperasi BMT Maslahah Mursalah li al Ummah yang disingkat menjadi BMT MMU.

Pada perkembangannya anggota bersepakat untuk merubah alih bina semula dibawah binaan Dinas Koperasi dan UKM Pasuruan menjadi binaan Dinas Koperasi dan UKM Provinsi Jawa TImur. Kemudian pada akhir bulan oktober 2013 KJKS BMT MMU Sidogiri Jawa TImur berubah nama menjadi KSPPS BMT Maslahah. ${ }^{2}$

Pada Bulan Desember Tahun 2019 Koperasi BMT Maslahah ini telah mempunyai 101 Kantor cabang dan 3 kantor kasyang tersebar diseluruh wilayah Jawa Timur yaitu di Kabupaten dan Kota Pasuruan sebanyak 23 kantor cabang dan 2 kantor kas, Kabupaten Probolinggo sebanyak 12 kantor cabang, Kabupaten Malang sebanyak 19 kantor cabang, Kabupaten Lumajang sebanyak 8 kantor cabang, Kabupaten Situbondo sebanyak 5 kantor cabang, Kabupaten Bondowoso 
sebanyak 3 kantor cabang, Kabupaten Jember sebanyak 3 kantor cabang, Kabupaten Mojokerto sebanyak 5 kantor cabang dan 1 kantor kas, Kabupaten Jombang sebanyak 3 kantor cabang, Kabupaten Sidoarjo sebanyak 4 kantor cabang, Surabaya sebanyak 7 kantor cabang, Kabupaten Gresik sebanyak 2 kantor cabang, dan Kabupaten Ngawi sebanyak 6 kantor cabang. ${ }^{3}$

\section{B. PRINSIP KEHATI-HATIAN DI KSPPS BMT MASLAHAH}

KSPPS BMT Maslahah adalah salah satu lembaga keuangan syariah yang kegiatannya adalah menghimpun simpanan anggota dan melakukan pinjaman dan pembiayaan kepada anggotanya dengan prinsip syariah sesuai dengan ketentuan pelaksanaan Dewan Syariah Nasional - Majelis Ulama Indonesia (DSN MUI).

Pada dasarnya KSPPS BMT Maslahah dengan lembaga keuangan lainnya seperti Perbankan Syariah memiliki sistem kerja yang hampir sama, lembaga keuangan syariah melaksanakan kegiatan usahnya harus menjalankan prinsip kehati-hatian.

Penerapan pada sektor jasa keuangan berbadan hukum Koperasi tunduk kepada Permen No. 39 Tahun 2007 tentang pedoman pengawasan koperasi jasa keuangan syariah dan usaha jasa keuangan syariah, Permen KUKM Nomor 21 Tahun 2008 tentang pedoman pengawasan koperasi simpan pinjam dan usaha simpan pinjam kopersi. Permen ini telah dicabut dan tidak berlaku dan digantikan dengan Permen KUKM nomor 17 tahung 2015 tentang pengawasan koperasi. Kepmen No. 16 Tahun 2016 tentang prinsip kehati-hatian, Undang-undang Nomor 8/2010 tentang tindak pidana pencucian Uang dan Peraturan Otoritas Jasa Keuangan nomor 12/POJK.01/2017 tentang penerapan program anti pencucian uang dan pencegahan pendanaan terorisme di sektor jasa keuangan. ${ }^{4}$

\footnotetext{
${ }^{3}$ Buku RAT Tahun buku 2019

${ }^{4}$ PERMENKOP dan UKM RI No. 17 Tahun 2015
} 
Prinsip kehati-hatian (prudential banking) merupakan asas yang menyatakan bahwa dalam menjalankan fungsinya dan kegiatan usaha wajib menerapkan prinsip kehati-hatian dengan tujuan agar bank dalam menjalankan usahanya harus secara baik dan benar dengan mematuhi ketentuan dan norma hokum yang berlaku. ${ }^{5}$ konsep inilah yang menjadi rujukan implementasi prinsip kehati-hatian dalam proses pengelolaan, dan menjadi fokus pembahasan prinsip kehatihatian yang tidak hanya mencakup aspek pembiayaan saja, akan tetapi mencakup hal yang lebih besar baik itu prinsip mengenal Anggota yang berhubungan dengan manajemen resiko pada pengelolaan KSPPS BMT Maslahah.

Pengelola KSPPS melaksanakan prinsip kehati-hatian (prudential principle) terutama dalam hal penyaluran pembiayaan, dengan berpegang kepada :

1. Prosedur penyaluran pembiayaan

2. Penerapan 5C Concept (Character, Capacity, Capital, Condition of Economics, Collateral)

3. Perbandingan cost and benefit

4. Sumber daya yang dimiliki KSPPS

5. Aspek manfaat

6. Likuiditas KSPPS

7. Tingkat resiko dari masing-masing pembiayaan

8. Kelangsungan hidup KSPPS.

Pengelola KSPPS memiliki keyakinan atas kemampuan dan kesanggupan anggota pembiayaan untuk melunasi pembiayaan yana akan diterima. Untuk memperoleh keyakinan pengelola KSPPS wajib melakukan penilaian terhadap anggota pembiayaan mengenal watak, kemampuan, modal, prospek usaha dan jaminan (jika diperlukan) ${ }^{6}$

${ }^{5}$ Usman $(2001: 18)$

${ }^{6}$ Modul Pelatihan Melakukan Prinsip-prinsip Pengelolaan Organisasi dan Manajemen KJKS Versi : 2016 
Prinsip kehati-hatian merupakan prinsip untuk melindungi pembiayaan dan berbagai permasalahan dengan cara mengenal customer (anggota) melalui identitas calon anggota, dokumen pendukung informasi dari calon anggota dan anggota lainnya. ${ }^{7}$

Pembiayaan kepada anggota dapat dikatakan berhasil apabila pembiayaan yang diberikan bermanfaat dan usaha anggota berkembang sehingga memberikan kepada anggota dan kepada KSPPS serta anggota dapat mengembalikan pembiayaan sesuai dengan perjanjian yang telah disepakati.

Dalam pelaksanaan prinsip kehati-hatian KSPPS BMT Maslahah melakukan beberapa indikator dan strategi pendekatan sebagai berikut :

\section{Capital adequacy ratio (CAR)}

Merupak indicator terhadap kemampuan KSPPS untuk menutupi penurunan aktivanya sebagai akibat dari kerugian yang disebabkan oleh aktiva yang beresiko.

2. Batas maksimum pemberian pembiayaan (BMPP)

Batas maksimum pemberian pembiayaan kepada anggota, mempunyai kebijakan khusus yang diatur dalam standar operasional prosedur (SOP) tersendiri.

3. Kewajiban Penyisihan Penghapusan Aktiva Produktif (PPAP).

PPAP merupakan penyisihan dari aktiva produktif yang masuk pada kategori lancar, dalam perhatian khusus, kurang lancar, diragukan dan macet. KSPPS wajib membentuk suatu penyisihan aktiva produktif yang cukup guna menutup risiko kerugian. Kewajjiban PPAP ini juga diatur dalam peraturan standar operasional prosedur (SOP) tersendiri.

4. Non Performing Financing (NPF).

Non Performing Financing (NPF) adalah pembiayaan bermasalah yang terdiri dari pembiayaan yang berklasifikasi

${ }^{7}$ Veithzal RIvai dkk (2008) 
pembiayaan kurang lancar, pembiayaan diragukan dan pembiayaan macet. Ukuran yang digunakan oleh KSPPS adalah dibawah lima persen. Semakin kecil angka NPF maka, semakin kecil pula tingkat risiko KSPPS.

5. Return on Asset (ROA).

Return on Asset (ROA) adalah rasio mengukur tingkat kemampuan Koperasi dalam menghasilkan laba dari aktiva yang digunakan. Yaitu perbandinga antara laba sebelum bagi hasil dan pajak (EBIT) dengan total aktiva yang dimiliki KSPPS . ROA yang positif adalah total aktiva yang digunakan KSPPS untuk beroperasi, mampu memberikan laba. Sebaliknya ROA yang negatif adalah total aktiva yang digunakan tidak mampu memberikan laba kepada KSPPS, bahkan mendapatkan kerugian dan akan menghambat pertumbuhan.

6. Net profit Margin (NPM).

Net Profit Margin adalah perbandingan antara total jumlah laba bersih dengan total jumlah pendapatan KSPPS. Hal ini digunakan untuk menentukan perolehan pendapatan tertentu yang bisa menghasilkan laba bersih secara maksimal.

7. Ketentuan Self Regulatory KSPPS.

Ketentuan Self Regulatory KSPPS yaitu pendekatan pengawasan yang dilakukan secara konsisten terhadap ketentuan intern yang dibuat sendiri dalam melaksanakan kegiatan operasional KSPPS dengan tetap mengacu pada prinsip kehatihatian $^{8}$ KSPPS BMT Maslahah telah melakukan program antara lain adalah :

a. Terbentuknya satuan pengawas internal (SPI).

b. Tugas dan kewenangan SPI adalah melakukan pengawasan terhadap operasional KSPPS.

\footnotetext{
${ }^{8}$ Modul Melakukan Prinsip-prinsip Pengelolaan Organisasi dan Manajemen KJKS Buku Informasi Versi: 2016
} 
c. Pengawasan SPI meliputi kinerja karyawan, kinerja keuangan dan kinerja operasional serta kinerja kelembagaan.

d. Pengawasan SPI berdasarkan pada membandingkan antara best fit dan best practice, yang dilakukan oleh karyawan.

e. Best fit adalah aturan yang berlaku pada KSPPS BMT Maslahah antara lain :

1) UU No. 25 Tahun 1992

2) Permen KUKM

3) ADART KSPPS BMT Maslahah

4) SOP KSPPS BMT Maslahah

5) SOM KSPPS BMT Maslahah

6) IK KSPPS BMT Maslahah

7) Persus KSPPS BMT Maslahah

8) Dan peraturan lainnya yang berlaku.

f. Best Practice adalah pelaksanaan kegiatan operasional yang dilakukan oleh karyawan KSPPS BMT Maslahah, apakah sudah sesuai dengan best fit yang sudah ditentukan.

\section{PINJAMAN DAN PEMBIAYAAN DI KSPPS BMT MASLAHAH}

Tahapan awal untuk melakukan pinjaman dan pembiayaan di KSPPS BMT MASLAHAH adalah harus memenuhi syarat administrasi, syarat kelayakan usaha, syarat modal sendiri, syarat jaminan dan syarat lainnya

Persyaratan administrasi yang harus dipenuhi oleh anggota pembiayaan adalah sebagai berikut :

1. Foto Copy identitas yang berlaku

2. Foto copy kartu keluarga

3. Foto copy akta nikah 
4. Surat pengajuan permohonan pembiayaan

5. Surat persetujuan suami/istri

6. Surat pernyataan pembiayaan dipakai sendiri

7. Surat keterangan bekerja dari perusahaan (jika karyawan)

8. Foto cop SK pengangkatan terakhir (jika ada)

9. Foto copy slip gaji tiga bulan terakhir (jika ada)

10. Foto copy rekening tabungan BMT

11. Foto copy slip pembayaran listrik, PDAM

12. Legalitas usaha untuk perorangan atau sektor usaha antara lain :

12.1. Foto copy NPWP (Nomor Pokok Wajib Pajak)

12.2. Foto copy TDP (Tanda Daftar Perusahaan)

12.3. Foto copy SITU (Surat Ijin Tempat Usaha)

12.4. Foto copy TDR (Tanda Daftar Rekanan)

12.5. Foto copy SIUJK (Surat Ijin Usaha Jasa Konstruksi)

12.6. Foto copy profile perusahaan

12.7. Foto copy dokumen lain yang mendukung.

13. Foto copy agunan atau jaminan pembiayaan

Agunan kendaraan bermotor atau mobil

13.1. Foto copy BPKB dan STNK kendaraan bermotor

13.2. Foto copy KIR (kendaraan niaga)

13.3. Foto copy surat trayek

13.4. Foto copy faktur

13.5. Surat keterangan kepemilikan dari pejabat setempat

13.6. Surat keterangan pelepasan kendaraan (dari perusahaan) Agunan Tanah bersertipikat

13.1. Foto copy sertipikat / surat tanah

13.2. Foto copy SPPT PBB

13.3. Foto copy IMB 
13.4. Surat kuasa bermaterai cukup darim pemilik surat tanah $(\text { jika ada })^{9}$

Persyaratan yang harus dipenuhi oleh anggota dalam melakukan pembiayaan yang kedua adalah syarat kelayakan usaha, bagaimana usaha yang akan dibiayai dapat dipastikan usahanya produktif dan sudah berjalan. Sehingga dapat dipastikan usaha yang dibiayai dapat berlangsung dengan baik dan berkesinambungan. Persyaratan ini dapat diklasifikasikan sebagai berikut :

1. Usaha anggota yang akan dibiayai sudah berjalan minimal 2 tahun

2. Usahanya sesuai prinsip syariah (halal)

3. Barang produksi, jasa, usaha, perdagangan, pertanian, peternakan, dan lainya merupakan kebutuhan pokok dalam perekonomian.

4. Bahan baku atau usahanya mudah diperoleh

5. Ada barang pengganti (substitusi)

6. Usahanya dikerjakan sendiri atau mempunyai sejumlah karyawan

7. Usahanya dapat dikembangkan dan diperluas

8. Omzet yang diperoleh harian atau bulanan

9. Omzet yang diperoleh cenderung meningkat

10. Usahanya dicatat atau dibukukan dengan baik ${ }^{10}$

Persyaratan yang ketiga adalah modal sendiri. Usaha anggota yang dibiayai biasanya sudah berjalan dan mempunyai modal sendiri. Sehingga usaha yang akan dibiayai benar-benar untuk mengembangkan usaha, memperluas jaringan, memperbanyak produksi, menambah usaha, menambah modal usaha dan mendapatkan tambahan laba usaha. Tanpa dibiayai oleh KSPPS BMT sebenarnya sudah dapat berjalan, akan tetapi karena kebutuhan usaha

\footnotetext{
${ }^{9}$ SOP KSPPS BMT MASLAHAH

${ }^{10}$ SOP KSPPS BMT MASLAHAH
} 
yang lebih besar, maka dapat menjadikan pembiayaan tersebut menjadi tambahan modal untuk pelaku usaha (Anggota).

Modal sendiri yang dimiliki oleh anggota terlebih dahulu dihitung menggunakan satuan nilai rupiah, seberapa besar nilai modal yang dimiliki tergantung pada kepemilikan Anggota. Modal sendiri bisa berupa asset tetap seperti gedung, bangunan, tanah, dan asset tidak tetap seperti kendaraan, mesin dan benda bergerak lainnya.

Modal sendiri diperhitungkan dengan nilai pinjaman yang diajukan oleh Anggota dengan menggunakan persentase. Seberapa besar nilai pinjaman yang layak untuk direalisasikan. Misalnya total modal sendiri adalah sebesar sepuluh juta rupiah, maka maksimal plafon maksimal pembiayaan yang bisa direalisasikan kepada Anggota adalah sebesar sepuluh juta rupiah atau jika menggunakan persentase adalah sebesar seratus persen dari modal yang dimiliki Anggota.

Persyaratan keempat adalah agunan, yang digunakan sebagai jaminan pembiayaan. Agunan bukan merupakan kewajiban secara mutlak yang harus dimiliki oleh Anggota sebagai syarat utama yang harus dimiliki. Akan tetapi agunan dipandang sebagai suatu bentuk kepercayaan kedua belah pihak untuk saling mengikatkan diri dalam perjanjian pembiayaan yang dilakukan.

Bentuk kepercayaan anggota yang benar-benar diwujudkan dalam bentuk penyerahan agunan adalah merupakan tuntunan syariat Islam. Apabila terjadi kelalayan atau wanprestasi terhadap pengikatan perjanjian pembiayaan maka, ada solusi pemecahan permasalahan yang sudah diatur dan disepakati oleh kedua belah pihak antara anggota sebagai debitur dan KSPPS BMT sebagai shohibul maal.

Penyerahan agunan dari pembiayaan yang diterima Anggota merupakan bentuk tanggung jawab Anggota agar saling memberikan rasa aman dan yang terpenting adalah sesuai dengan prinsip syariah, 
yaitu unsur keadilan tidak ada unsur merugikan salah satu pihak, atau mengandung unsur penipuan.

Bagi KSPPS BMT Maslahah agunan adalah merupakan bentuk kehati-hatian yang dilakukan untuk memastikan bahwa pembiayaan yang direalisasikan telah memenuhi prinsip-prinsip koperasi yaitu prinsip kehati-hatian. Prinsip ini sesuai dengan peraturan perundangundangan yang berlaku baik pada perbankan maupun pada lembaga non bank seperti koperasi.

Ketentuan tentang persyaratan agunan dalam KSPSS sebagai berikut :

1. Agunan milik sendiri

2. Surat kuasa penyerahan agunan (jika milik orang lain)

3. Agunan dapat dikuasai, bukan hak pakai

4. Usia agunan (jika benda bergerak seperti mesin, motor dan mobil)

5. Agunan atas nama sendiri (jika sertipikat)

6. Agunan bersertipikat berdiri diatasnya bangunan

7. Usia bangunan diatas tanah bersertipikat. ${ }^{11}$

Undang-undang no. 7 tahun 1992 tentang Perbankan dan POJK nomor 9 tahun 2016 tentang prinsip kehati-hatian bagi bank yang melakukan penyerahan sebagian pelaksanaan pekerjaan kepada pihak lain ${ }^{12}$ adalah landasan prinsip kehati-hatian Koperasi BMT MASLAHAH dalam menjalankan usahanya dalam hal pinjaman dan pembiayaan.

Prinsip kehati-hatian Koperasi BMT MASLAHAH yang dilakukan adalah membuat peraturan khusus seperti standar operasional prosedur pengajuan pembiayaan anggota, standar operasional prosedur analisa pembiayaan, dan standar operasional

\footnotetext{
${ }^{11}$ SOP KSPPS BMT MASLAHAH

${ }^{12}$ Undang-undang no. 7 tahun 1992 dan POJK nomor 9 tahun 2016
} 
prosedur realisasi pembiayaan. Sehingga pinjaman dan pembiayaan benar-benar dilakukan sesuai dengan prosedur yang telah ditetapkan.

\section{KESIMPULAN}

Dari materi diatas yang terdapat dari sebuah jurnal ini terdapat kesimpulan yang dapat peneliti uraikan yaitu sebagai berikut :

1. Perkoperasian menjadi suatu sistem dalam kehidupan ekonomi masyarakat untuk memenuhi kebutuhan hidup dan memecahkan permasalahan ekonomi yang dihadapi.

2. BMT MMU Sidogiri yang berkedudukan di Kecamatan Wonorejo Kabupaten Pasuruan telah berdiri 23 tahun dantelah berkembang dengan pesat. Banyak cabang yang telah didirikan.

3. Penerapan pada sektor jasa keuangan berbadan hukum Koperasi tunduk kepada Permen No. 39 Tahun 2007 tentang pedoman pengawasan koperasi jasa keuangan syariah dan usaha jasa keuangan syariah, Permen KUKM Nomor 21 Tahun 2008 tentang pedoman pengawasan koperasi simpan pinjam dan usaha simpan pinjam kopersi.

4. Prinsip kehati-hatian merupakan prinsip untuk melindungi pembiayaan dan berbagai permasalahan dengan cara mengenal customer (anggota) melalui identitas calon anggota, dokumen pendukung informasi dari calon anggota dan anggota lainnya.

5. Dalam pelaksanaan prinsip kehati-hatian KSPPS BMT Maslahah melakukan beberapa indikator dan strategi pendekatan sebagai berikut :
a. Capital adequacy ratio (CAR)
b. Batas maksimum pemberian pembiayaan (BMPP)
c. Kewajiban Penyisihan Penghapusan Aktiva Produktif (PPAP).
d. $\quad$ Non Performing Financing (NPF).
e. Return on Asset (ROA).
f. Net profit Margin (NPM). 


\section{g. Ketentuan Self Regulatory KSPPS.}

6. Adapun dalam pemiayaan ada beberapa persyaratan administrasi yang harus dipenuhi oleh anggota pembiayaan adalah sebagai berikut :
a. Foto Copy identitas yang berlaku
b. Foto copy kartu keluarga
c. Foto copy akta nikah
d. Surat pengajuan permohonan pembiayaan
e. Surat persetujuan suami/istri
f. Surat pernyataan pembiayaan dipakai sendiri
g. Surat keterangan bekerja dari perusahaan (jika karyawan)
h. Foto cop SK pengangkatan terakhir (jika ada)
i. $\quad$ Foto copy slip gaji tiga bulan terakhir (jika ada)
j. Foto copy rekening tabungan BMT
k. Foto copy slip pembayaran listrik, PDAM
1. Legalitas usaha untuk perorangan atau sektor usaha
m. Foto copy agunan atau jaminan pembiayaan 


\section{DAFTAR PUSTAKA}

Buku RAT Tahun buku 2019

Modul Pelatihan Melakukan Prinsip-prinsip Pengelolaan Organisasi dan Manajemen KJKS Versi : 2016

Modul Pelatihan Melakukan Prinsip-prinsip Pengelolaan Organisasi dan Manajemen KJKS Versi : 2016

Ninik Widiyanti, Sunindhia,Y.W. 2003. "Koperasi dan Perekonomian Indonesia Cetakan keempat”. Jakarta : Rineka Cipta

PERMENKOP dan UKM RI No. 17 Tahun 2015

Selayang Pandang Koperasi BMT Maslahah

SOP KSPPS BMT MASLAHAH

Undang-undang no. 7 tahun 1992 dan POJK nomor 9 tahun 2016 